Pacific Journal of Mathematics

SOME TOPOLOGICAL PROPERTIES WEAKER THAN 


\title{
SOME TOPOLOGICAL PROPERTIES WEAKER THAN COMPACTNESS
}

\author{
G. Goss AND G. VIGLino
}

Many topological properties may be described by covering relations which may also generally be easily described in terms of filter relations. For example, a space is compact if and only if each open cover of the space contains a finite subcover, or equivalently, if each filter has an adherent point. In this paper, characterizations are given of some topological properties weaker than compactness, both in terms of filters and coverings. In the final section a question posed by Viglino and by Dickman and Zame is answered.

2. Definitions and notations. (a) A space for which distinct points may be separated by disjoint closed neighborhoods (i.e., a Urysohn space) will be labeled a $T_{2(1 / 2)}$-space. Let $\nu=2,2 \frac{1}{2}$, or 3 . A $T_{\nu}$-space is said to be $T_{\nu}$-closed if it is closed in each $T_{\nu}$-extension. A $T_{\nu}$-space $(X, \tau)$ is said to be $T_{\nu}$-minimal if there exists no $T_{\nu}$ topology on $X$ strictly weaker than $\tau$.

(b) A Hausdorff space $(X, \tau)$ is $C$-compact if given a closed set $Q$ of $X$ and a $\tau$-open cover $\mathcal{O}$ of $Q$, then there exists a finite number of elements of $\mathcal{O}$, say $0_{i}, 1 \leqq i \leqq n$, with $Q \subset \operatorname{cl}_{X} \bigcup_{i=1}^{n} 0_{i}$.

(c) A Hausdorff space $X$ is functionally compact if for every open filter $\mathscr{U}$ in $X$ such that the intersection $A$ of the elements of $\mathscr{U}$ equals the intersection of the closures of the elements of $\mathscr{C}$, then $\mathscr{C}$ is the neighborhood filter of $A$.

(d) A filter is open (closed) if it has a base of open (closed) sets. A regular filter is a filter which is both open and closed.

(e) Let $A$ be a subset of a space $X$. An open cover, $\mathscr{U}$, of $A$ will be said to be a Urysohn cover if for each $x \in A$ there exist elements $0_{1}, 0_{2}$ of $\mathscr{C}$ with $x \in 0_{1} \subset \operatorname{cl} 0_{1} \subset 0_{2}$.

(f) Let $A$ be a subset of a space $X$. An open cover, $\mathscr{S}$, of $A$ will be said to be a strong cover if for each $x \in A$ there exist $\left\{0_{n}\right\}_{n=1}^{\infty} \subset \mathscr{S}$ with $x \in 0_{1}$ and cl $0_{i} \subset 0_{i+1}$ for each $i$.

(g) A closed subset $Y$ of a space $X$ is regular closed if given $x \in X \backslash Y$, then there exists an open set 0 with $x \in 0 \subset \operatorname{cl} 0 \subset Y^{c}$.

3. Covering theorems. Filter characterizations for $T_{\nu}$-closed and $T_{\nu}$-minimal spaces are listed below. The proof of (a) may be found in [2]; (b) in [1]; (c), (d), and (e) in [5]; (f) in [4].

Theorem I. (a) $A T_{2}$-space is $T_{2}$-closed if and only if every 
open filter has an adherent point.

(b) $A T_{2}$-space is $T_{2}$-minimal if and only if every open filter with unique adherent point converges.

(c) $A T_{2(1 / 2)}$-space is $T_{2(1 / 2)}$-closed if and only if for each two open filters $\mathscr{F}_{1}, \mathscr{F}_{3}$ and each closed filter $\mathscr{F}_{2}$ such that $\mathscr{F}_{1} \subset \mathscr{F}_{2} \subset \mathscr{F}_{3}$, then $\mathscr{F}_{1}$ has an adherent point.

(d) $A T_{2(1 / 2)}$-space is $T_{2(1 / 2)}$-minimal if and only if for each two open filters $\mathscr{F}_{1}, \mathscr{F}_{3}$ and each closed filter $\mathscr{F}_{2}$ such that $\mathscr{F}_{1} \subset \mathscr{F}_{2} \subset \mathscr{F}_{3}$ with $\mathscr{F}_{1}$ having a unique adherent point, then $\mathscr{F}_{3}$ converges.

(e) $A T_{3}$-space is $T_{3}$-closed if and only if every regular filter has an adherent point.

(f) $A T_{3}$-space is $T_{3}$-minimal if and only if every regular filter with unique adherent point converges.

Of the six properties listed in the above theorem, only the first has a well known covering characterization. (See Theorem II $\left(a^{\prime}\right)$, below). Herrlick has listed in [5] covering characterizations for $T_{2(1 / 2)^{-}}$ closed and $T_{3}$-closed spaces. We list in the following theorem covering characterizations for each of the six properties. These characterizations emphasize the relationship between $T_{\nu}$-closed and $T_{\nu}$-minimal spaces. The proof of each part of Theorem II follows from its counterpart in Theorem I. We offer proofs for parts $\left(d^{\prime}\right)$ and $\left(f^{\prime}\right)$.

Theorem II. (a') $A T_{2}$-space $X$ is $T_{2}$-closed if and only if given an open cover, $\mathcal{O}$, of $X$, then there exists $0_{i} \in \mathcal{O}, 1 \leqq i \leqq n$, such that $X=\operatorname{cl~} \bigcup_{i=1}^{n} 0_{i}$.

(b') $A T_{2}$-space $X$ is $T_{2}$-minimal if and only if given $p \in X$, an open cover, $\mathcal{O}$, of $X \backslash\{p\}$, and an open neighborhood $U$ of $p$, then there exist $0_{i} \in \mathcal{O}, 1 \leqq i \leqq n$, such that $X=U \cup \mathrm{cl} \bigcup_{i=1}^{n} 0_{i}$.

(c') A $T_{2(1 / 2)}$-space $X$ is $T_{2(1 / 2)}$ closed if and only if given a Urysohn cover, $\mathscr{U}$ of $X$, then there exist $0_{i} \in \mathscr{U}, 1 \leqq i \leqq n$, such that $X=$ $\mathrm{cl} \bigcup_{i=1}^{n} 0_{i}$.

(d') $A T_{2(1 / 2)}$-space $X$ is $T_{2(1 / 2)}$-minimal if and only if given $p \in X$, a Urysohn cover, $\mathscr{\mathscr { C }}$ of $X \backslash\{p\}$ and an open neighborhood $U$ of $p$, then there exist $0_{i} \in \mathscr{Q}, 1 \leqq i \leqq n$, such that $X=U \cup \operatorname{cl} \bigcup_{i=1}^{n} 0_{i}$.

(e') $A T_{3}$-space $X$ is $T_{3}$-closed if and only if given a strong cover, $\mathscr{S}$, of $X$, then there exist $0_{i} \in \mathscr{S}, 1 \leqq i \leqq n$, such that $X=\bigcup_{i=1}^{n} 0_{i}$.

(f') $A T_{3}$-space $X$ is $T_{3}$-minimal if and only if given $p \in X, a$ strong cover, $\mathscr{S}$, of $X \backslash\{p\}$, and an open neighborhood $U$ of $p$, then there exist $0_{i} \in \mathscr{S}, 1 \leqq i \leqq n$, such that $X=U \cup \bigcup_{i=1}^{n} 0_{i}$.

Proof of $\left(\mathrm{d}^{\prime}\right)$. Let $p \in X, U$ an open neighborhood of $p$, and $\mathscr{U}$ a Urysohn cover of $X \backslash\{p\}$ such that the union of the closure of any 
finite number of elements of $\mathscr{U}$ fails to cover $U^{c}$. Since $X$ is $T_{2(1 / 2)}$, we may assume that for each $x \in X \backslash\{p\}$ there exist $0_{x}^{1}, 0_{x}^{3}$ in $\mathscr{C}$ with $x \in 0_{x}^{1} \subset \operatorname{cl~} 0_{x}^{1} \subset 0_{x}^{3}$, and $p \neq 0_{x}^{3}$. Let $\mathscr{F}_{3}$ denote the filter generated by $\left\{0_{x}^{3}\right\}_{x \in X /\{p\}}, \mathscr{F}_{1}$ the filter generated by $\left\{\overline{0}_{x}^{11}\right\}_{x \in X /\{p\}}$, and $\mathscr{F}_{2}$ the filter generated by $\left\{{\overline{0 \overline{0_{x}^{3 c}}}}_{x \in X /\{p\}}\right.$. Then $\mathscr{F}_{1} \subset \mathscr{F}_{2} \subset \mathscr{F}_{3}$ with $p$ the only adherent point of $\mathscr{F}_{1}$ and $\mathscr{F}_{3}$ not converging.

Conversely, let $\mathscr{F}_{1} \subset \mathscr{F}_{2} \subset \mathscr{F}_{3}$ with $\mathscr{F}_{1}$ having a unique adherent point, $p$, and $\mathscr{F}_{3}$ not converging. Let $U$ be an open neighborhood of $p$ which contains no element of $\mathscr{F}_{3}$. Then, $\mathscr{U}=\left\{\bar{F}_{1}^{c} / F_{1} \in \mathscr{F}_{1}\right\} \cup$ $\left\{\bar{F}_{3}^{c} / F_{3} \in \mathscr{F}_{3}\right\}$ is a Urysohn cover of $X \backslash\{p\}$ such that union of the closure of any number of elements of $\mathscr{U}$ fails to cover $U^{c}$.

Proof of $\left(\mathrm{f}^{\prime}\right)$. Let $p \in X, U$ an open neighborhood of $p$, and $\mathscr{S}$ a strong cover of $X \backslash\{p\}$ such that the union of any finite number of elements of $\mathscr{S}$ fails to cover $U^{c}$. Since $X$ is $T_{3}$, we may assume that for each $x \in X \backslash\{p\}$ there exist a sequence $\left\{0_{x}^{n}\right\}_{n=1}^{\infty}$ of elements of $\mathscr{S}$ with $x \in 0_{x}^{1}, \operatorname{cl} 0_{x}^{n} \subset 0_{x}^{n+1}$ and $p \notin 0_{x}^{n}$ for any $n$. Now, the filter generated by $\left\{\overline{0_{x}^{n c}} / x \in X \backslash\{p\} ; n=1,2,3, \cdots\right\}$ is regular with unique adherent point, $P$, and does not converge.

Conversely, let $\mathscr{F}$ be a regular filter with unique adherent point, $p$. Let $U$ be an open neighborhood of $p$ which contains no element of $\mathscr{F}$. Then $\left\{\bar{F}^{c} / F \in \mathscr{F}\right\}$ is a strong cover of $X \backslash\{p\}$ and no finite union of elements of this cover contains $U^{c}$.

By replacing in Theorem II ( $\left.\mathrm{b}^{\prime}\right)$ the point, $p$, by a closed (regular closed) set, we obtain the covering characterization for $C$-compact (functionally compact) spaces listed below. The proof follows easily from definition $b(c)$.

TheOREM III. $A T_{2}$-space $X$ is C-compact (functionally compact) if and only if given a closed (regular closed) subset $C$ of $X$, an open cover $O$, of $X \backslash C$, and an open neighborhood $U$ of $C$, then there exist $0_{i} \in \mathcal{O}, 1 \leqq i \leqq n$, such that $X=U \cup \operatorname{cl} \bigcup_{i=1}^{n} 0_{i}$.

4. A counterexample. One can easily show that every continuous function from a $C$-compact space into a Hausdorff space is closed [6]. The question as to whether or not the converse is valid was posed in [6]. Dickman and Zame [4] have since then shown that a necessary and sufficient condition that a Hausdorff space be functionally compact is that each continuous function of the space into a Hausdorff space be closed. We resolve the question posed in [6] by constructing, in the following example, a space which is functionally compact but not $C$-compact. The example is a modification of that given in [4] showing that a functionally compact space need not be compact. 
ExAMPLE. Let $I=[0,1]$. For each integer $n \geqq 2$, let $\left\{a_{n}^{j}\right\}_{j=1}^{\infty}$ be a strictly decreasing sequence in $(1 / n, 1 / n-1)$ converging to $1 / n$. Let $X=I \backslash \bigcup_{n \geq 2}^{j \geq 1}\left\{a_{n}^{j}\right\}$. Topologize $X$ as follows: Let $X \backslash\left(\{1 / n\}_{n=1}^{\infty} \cup\{0\}\right)$ retain the usual topology. Let a neighborhood system of the point 0 be composed of all sets of the form $\{x \in X /|x|<1 / m\} \backslash\{1 / n\}_{n=1}^{\infty}, m$ an integer. Let a neighborhood system of the point $1 / n$ be composed of all sets of the form $0 \cap X$ where 0 is an open set in $I$ with $\left\{1 / n, a_{n-1}^{1}, a_{n-3}^{2}, \cdots, a_{2}^{n-1 / 2}\right\} \subset 0$ in the case that $n$ is odd, and with $\left\{1 / n, a_{n-1}^{1}, a_{n-3}^{2}, \cdots, a_{3}^{n / 2-1}\right\} \subset 0$ in the case that $n$ is even (where for $n=2$ we simply have $\{1 / 2\})$. Clearly $X$ is Hausdorff. Let $0_{2 n}=$ $\{x \in X /|x-1 / 2 n|<1 / 3 n\} \cup \bigcup_{i=1}^{n-1}\left\{x \in X /\left|x-a_{2 n-2 i+1}^{i}\right|<1 / 3 n\right\}$ for each $n>1$. Then $\left\{0_{2 n}\right\}_{n>1}$ is an open cover of the closed set $\{1 / 2 n\}_{n>1}$ and the closure of any finite union of elements in $\left\{0_{2 n}\right\}_{n>1}$ fails to contain $\{1 / 2 n\}_{n>1}$. Hence, $X$ is not $C$-compact. We apply Theorem III and show that $X$ is functionally compact.

Let $C$ be a regular closed subset of $X, \mathcal{O}$ an open cover of $X \backslash C$, $U$ an open neighborhood of $C$. Suppose first that $C$ contains infinitely many elements of $\{1 / n\}_{n=1}^{\infty}$. Then by the regularity of $C,\{1 / n\}_{n=1}^{\infty} U$ $\{0\} \subset C$ so that $X \backslash U$ is compact. Suppose that $0 \in C$ and that only finitely many elements of $\{1 / n\}_{n=1}^{\infty}$ are contained in $C$. Choose $1 / 2 n$ and $1 / 2 n+1$ such that neither is in $C$. Let $0_{2 n}, 0_{2 n+1}$ be elements of $\infty$ containing $1 / 2 n$ and $1 / 2 n+1$ respectively. Then, $\{1 / n / n \geqq k\} \subset$ $\operatorname{cl}\left(0_{2 n} \cup 0_{2 n+1}\right)$ for some $k$. It is easy to see that the closure of a finite number of elements of $\mathcal{O}$ contains $X \backslash\left(\operatorname{cl}\left(0_{2 n} \cup 0_{2 n+1}\right) \cup U\right)$. Suppose that $0 \notin C$ and that only finitely many elements of $\{1 / n\}_{n=1}^{\infty}$ are contained in $C$. Once more let $0_{2 n}, 0_{2 n+1}$ be elements of $\mathcal{O}$ containing $1 / 2 n$ and $1 / 2 n+1$ respectively, with neither $1 / 2 n$ nor $1 / 2 n+1$ in $C$. Let $0_{i}$ be an element of $O$ containing 0 . It is easy to see that the closure of a finite number of elements of $\mathscr{O}$ contains $X \backslash\left(\operatorname{cl}\left(0_{i} \cup 0_{2 n} \cup\right.\right.$ $\left.\left.0_{2 n+1}\right) \cup U\right)$. Hence, $X$ is functionally compact.

\section{REFERENCES}

1. M. P. Berri, Minimal topological spaces, Trans. Amer. Math. Soc. 108 97-105.

2. M. P. Berri and R. Sorgenfrey, Minimal regular spaces, Proc. Amer. Math. Soc. 14 (1963), 454-458.

3. N. Bourbaki, Topologie Generale, $3^{e}$ ed, Ch. I, II, Hermann, Paris, 1961.

4. R. F. Dickman, Jr. and A. Zame, Functionally compact spaces, Pacific J. Math. 31 (1969), 303-312.

5. H. Herrlich, $T_{\nu}$-Abgeschlossenheit und $T_{\nu}$-Minimalität, Math. Zeit. 88 (1965), 285-294.

6. G. Viglino, C-compact spaces, Duke J. Math. 36 (1969), 761-764.

Received February 12, 1970. 


\section{PACIFIC JOURNAL OF MATHEMATICS}

\section{EDITORS}

\author{
H. SAMELSON \\ Stanford University \\ Stanford, California 94305 \\ Richard Pierce \\ University of Washington \\ Seattle, Washington 98105
}

\author{
J. DugundJI \\ Department of Mathematics \\ University of Southern California \\ Los Angeles, California 90007 \\ RICHARD ARENS \\ University of California \\ Los Angeles, California 9.0024
}

\section{ASSOCIATE EDITORS}

\begin{tabular}{|c|c|}
\hline E. F. BECKENBACH & K. YoshidA \\
\hline \multicolumn{2}{|c|}{ SUPPORTING INSTITUTIONS } \\
\hline UNIVERSITY OF BRITISH COLUMBIA & STANFORD UNIVERSITY \\
\hline CALIFORNIA INSTITUTE OF TECHNOLOGY & UNIVERSITY OF TOKYO \\
\hline UNIVERSITY OF CALIFORNIA & UNIVERSITY OF UTAH \\
\hline MONTANA STATE UNIVERSITY & WASHINGTON STATE UNIVERSITY \\
\hline UNIVERSITY OF NEVADA & UNIVERSITY OF WASHINGTON \\
\hline NEW MEXICO STATE UNIVERSITY & $* \quad * \quad *$ \\
\hline OREGON STATE UNIVERSITY & AMERICAN MATHEMATICAL SOCIETY \\
\hline UNIVERSITY OF OREGON & CHEVRON RESEARCH CORPORATION \\
\hline OSAKA UNIVERSITY & TRW SYSTEMS \\
\hline UNIVERSITY OF SOUTHERN CALIFORNIA & NAVAL WEAPONS CENTER \\
\hline
\end{tabular}

The Supporting Institutions listed above contribute to the cost of publication of this Journal, but they are not owners or publishers and have no responsibility for its content or policies.

Mathematical papers intended for publication in the Pacific Journal of Mathematics should be in typed form or offset-reproduced, (not dittoed), double spaced with large margins. Underline Greek letters in red, German in green, and script in blue. The first paragraph or two must be capable of being used separately as a synopsis of the entire paper. The editorial "we" must not be used in the synopsis, and items of the bibliography should not be cited there unless absolutely necessary, in which case they must be identified by author and Journal, rather than by item number. Manuscripts, in duplicate if possible, may be sent to any one of the four editors. Please classify according to the scheme of Math. Rev. Index to Vol. 39. All other communications to the editors should be addressed to the managing editor, Richard Arens, University of California, Los Angeles, California, 90024.

50 reprints are provided free for each article; additional copies may be obtained at cost in multiples of 50 .

The Pacific Journal of Mathematics is published monthly. Effective with Volume 16 the price per volume (3 numbers) is $\$ 8.00$; single issues, $\$ 3.00$. Special price for current issues to individual faculty members of supporting institutions and to individual members of the American Mathematical Society: $\$ 4.00$ per volume; single issues $\$ 1.50$. Back numbers are available.

Subscriptions, orders for back numbers, and changes of address should be sent to Pacific Journal of Mathematics, 103 Highland Boulevard, Berkeley, California, 94708.

PUBLISHED BY PACIFIC JOURNAL OF MATHEMATICS, A NON-PROFIT CORPORATION

Printed at Kokusai Bunken Insatsusha (Internatıonal Academic Printing Co., Ltd.), 7-17, Fujimi 2-chome, Chiyoda-ku, Tokyo, Japan. 


\section{Pacific Journal of Mathematics}

\section{Vol. 35, No. $3 \quad$ November, 1970}

John D. Arrison and Michael Rich, On nearly commutative degree one algebras . . . 533

Bruce Alan Barnes, Algebras with minimal left ideals which are Hilbert spaces . . . . 537

Robert F. Brown, An elementary proof of the uniqueness of the fixed point index . . . 549

Ronn L. Carpenter, Principal ideals in F-algebras .................... 559

Chen Chung Chang and Yiannis (John) Nicolas Moschovakis, The Suslin-Kleene

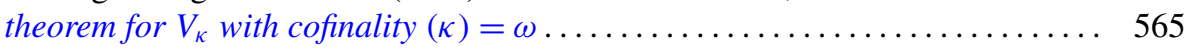

Theodore Seio Chihara, The derived set of the spectrum of a distribution

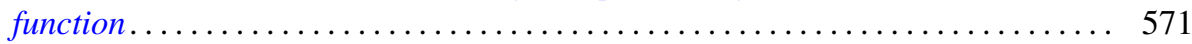

Tae Geun Cho, On the Choquet boundary for a nonclosed subspace of $C(S) \ldots \ldots \quad 575$

Richard Brian Darst, The Lebesgue decomposition, Radon-Nikodym derivative,

conditional expectation, and martingale convergence for lattices of sets .......

David E. Fields, Dimension theory in power series rings . . . . . . . . . . . .

Michael Lawrence Fredman, Congruence formulas obtained by counting

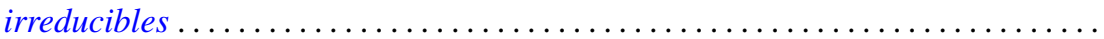

John Eric Gilbert, On the ideal structure of some algebras of analytic functions.....

G. Goss and Giovanni Viglino, Some topological properties weaker than

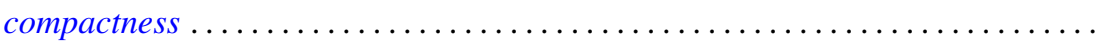

581

601

625

George Grätzer and J. Sichler, On the endomorphism semigroup (and category) of

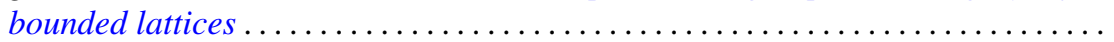

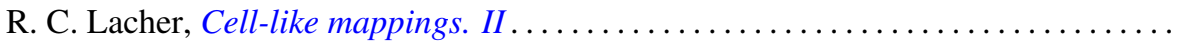

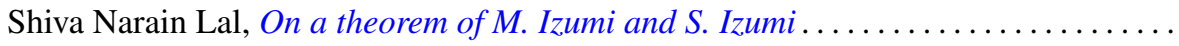

661

Howard Barrow Lambert, Differential mappings on a vector space ...............

Richard G. Levin and Takayuki Tamura, Notes on commutative power joined

semigroups.

Robert Edward Lewand and Kevin Mor McCrimmon, Macdonald's theorem for quadratic Jordan algebras.

J. A. Marti, On some types of completeness in topological vector spaces ....

Walter J. Meyer, Characterization of the Steiner point

717

Saad H. Mohamed, Rings whose homomorphic images are $q$-rings ...

727

Thomas V. O'Brien and William Lawrence Reddy, Each compact orientable surface

of positive genus admits an expansive homeomorphism ...

737

Robert James Plemmons and M. T. West, On the semigroup of binary relations...

743

Calvin R. Putnam, Unbounded inverses of hyponormal operator . .

755

William T. Reid, Some remarks on special disconjugacy criteria for differential

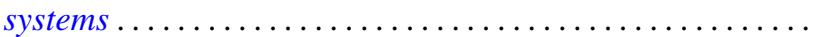

C. Ambrose Rogers, The convex generation of convex Borel sets in euclidean

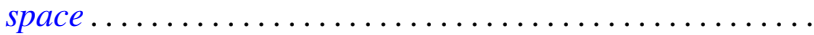

S. Saran, A general theorem for bilinear generating functions .

S. W. Smith, Cone relationships of biorthogonal systems ......

Wolmer Vasconcelos, On commutative endomorphism rings ....

795

Vernon Emil Zander, Products of finitely additive set functions from Orlicz

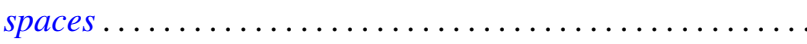

G. Sankaranarayanan and C. Suyambulingom, Correction to: "Some renewal

theorems concerning a sequence of correlated random variables" .

Joseph Zaks, Correction to: "Trivially extending decompositions of $E^{n}$ ”....... 805

Dong Hoon Lee, Correction to: "The adjoint group of Lie groups" ............ 805

James Edward Ward, Correction to: "Two-groups and Jordan algebras". 